\title{
The genome and proteome of Serratia bacteriophage $\eta$ which forms unstable lysogens
}

\author{
Jenna M Denyes ${ }^{1,6}$, Peter J Krell ${ }^{1}$, Richard A Manderville², Hans-Wolfgang Ackermann², Yi-Min She ${ }^{4}$ \\ and Andrew M Kropinski ${ }^{1,5^{*}}$
}

\begin{abstract}
Background: Serratia marcescens phage $\eta$ is a temperate unclassified member of the Siphoviridae which had been reported as containing hypermodified guanine residues.

Methods: The DNA was characterized by enzymatic digestion followed by HPLC analysis of the nucleoside composition, and by DNA sequencing and proteomic analysis. Its ability to form stable lysogens and integrate was also investigated.

Results: Enzymatic digestion and HPLC analysis revealed phage $\eta$ DNA did not contain modified bases. The genome sequence of this virus, determined using pyrosequencing, is 42,724 nucleotides in length with a mol\% GC of 49.9 and is circularly permuted. Sixty-nine putative CDSs were identified of which 19 encode novel proteins. While seven close genetic relatives were identified, they shared sequence similarity with only genes 40 to 69 of the phage $\eta$ genome, while gp1 to gp39 shared no conserved relationship. The structural proteome, determined by SDS-PAGE and mass spectrometry, revealed seven unique proteins. This phage forms very unstable lysogens with its host $S$. marcescens.
\end{abstract}

Keywords: Serratia marcescens, Phage evolution, Genome, Proteome, Bioinformatics, Lysogeny, Unstable lysogeny, Modified nucleosides, Siphoviridae

\section{Background}

Serratia marcescens is a Gram-negative opportunistic human pathogen belonging to the family Enterobacteriaceae. In humans it is of particular concern for patients with indwelling medical devices [1]. Outbreaks are almost exclusively caused by contaminated medical solutions or equipment, with $S$. marcescens even growing in antiseptic solutions [2]. Only recently, community acquired infections have been identified [3,4], which highlight the growing importance of this pathogen. Treatment of infections is possible with combinations of antibiotics; however the number of clinical strains resistant to multiple antibiotics is on the rise [5,6], including isolates which produce extended spectrum beta-lactamases $[7,8]$. Phage therapy might prove a viable alternative, but historically phages infecting $S$. marcescens were isolated solely

\footnotetext{
*Correspondence: kropinsk@queensu.ca

${ }^{1}$ Department of Molecular \& Cellular Biology, University of Guelph, Guelph, ON N1G 2W1, Canada

${ }^{5}$ Laboratory for Foodborne Zoonoses, Public Health Agency of Canada, 110 Stone Road West, Guelph, Ontario N1G 3W4, Canada

Full list of author information is available at the end of the article
}

for use in bacterial typing systems $[9,10]$ or for the transductional mapping of the genome $[11,12]$ and their biology remains poorly understood [13].

There are 87 named Serratia bacteriophages listed in Bacteriophage Names 2000 (http://www.phage.org/names/ 2000/) belonging to the Siphoviridae [14], Myoviridae [15], and Podoviridae [12] families of tailed phages. Since 2000, only a limited number of additional Serratia phages have been isolated and characterized. Phages PPV [16] and KSP100 [17] belong to family Podoviridae; the former being a tentative member of the T7likevirus genus, while the latter KSP100 is a member of the Phieco32likevirus genus. Only one additional siphovirus, phage SM701, has been described [18]. All other newly characterized phages are all members of the Myoviridae. These include the virulent generalized transducing phage фIF3 (phiIF3) [11], фMAM1 (phiMAM1) [19] which is related to the newly proposed Viunalikevirus [20], and phages KSP20 and KSP90 [17]. Phylogenetic analysis based upon limited sequence data suggests that KSP20 with its $32 \mathrm{~kb}$ genome is part of the Peduovirinae [21], while KSP90 is part of the T4 superfamily. 
S. marcescens bacteriophages were chosen as the focus of our research because of the growing importance of the host and its increasing prevalence as a nosocomial pathogen. Bacteriophage $\eta$ was selected for further study. This virus was isolated from an overnight culture supernatant of S. marcescens ES, in 1960 in Germany [22]. Of considerable interest was von Lohr's observation that the phage DNA displayed a discrepancy between the mol\% GC calculated from melting temperature (Tm) and buoyant density determinations suggesting the presence of a hypermodified base. Preliminary data suggested a hypermodified guanine [22].

\section{Resrults and discussion}

\section{Phage morphology and basic biology}

Phage $\eta$ is a B1 siphovirus [23,24] with an icosahedral head of $60 \mathrm{~nm}$ and a tail of $112 \times 8 \mathrm{~nm}$ which ends in a base plate with three conspicuous spikes (Figure 1). As such, phage $\eta$ is morphologically identical to the Jersey species of Salmonella phages [23,24].

The phage produces variably sized plaques when grown on $S$. marcescens using the double-agar overlay technique. The larger size plaque was approximately $3 \mathrm{~mm}$ in diameter, and the smaller only $1.5 \mathrm{~mm}$. Both plaque types were turbid, with greater turbidity in the plaque centers. The distribution of turbidity in both plaque types was the same and they arose equally from subcultures of both small and large plaque types.

\section{Phage $\boldsymbol{\eta}$ forms highly unstable lysogens with its host}

Phage-insensitive bacterial strains were selected from turbid plaques and serially propagated to remove any traces of contaminating exogenous phage. Lysogenic strains were distinguished from resistant strains by testing for the ability of chloroform-treated culture supernatants to form

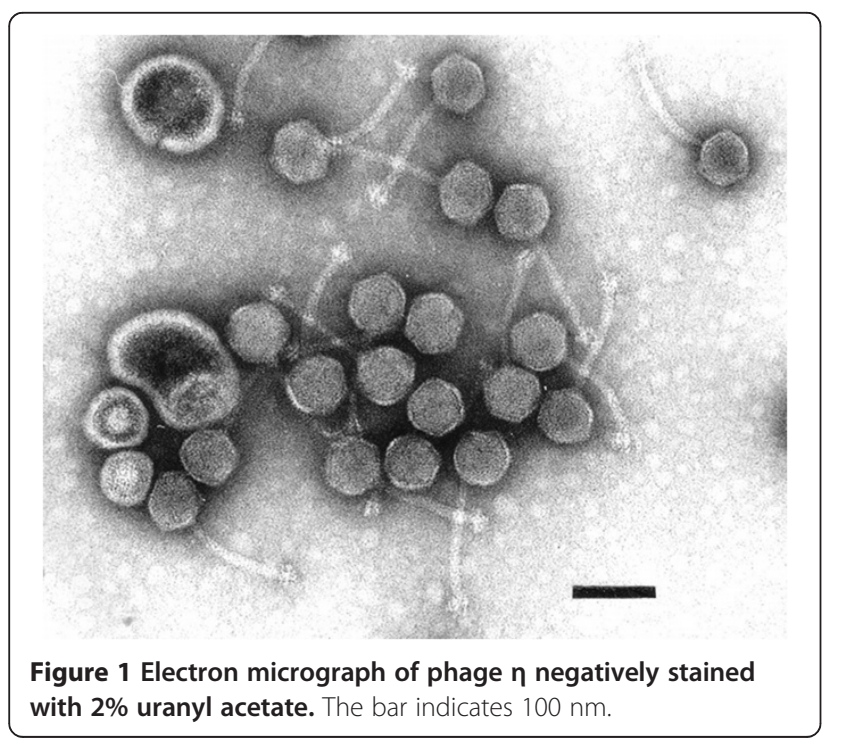

plaques on the wild type strain, for resistance to superinfection, and PCR reactions with phage $\eta$ specific primers (data not shown). Initial subcultures were resistant to superinfection, spontaneous release of phage in absence of an induction agent to a titre of $10^{7} \mathrm{PFU} / \mathrm{ml}$, and $10^{9} \mathrm{PFU} /$ $\mathrm{ml}$ when induced with mitomycin $\mathrm{C}$. In addition, phagespecific amplicons were observed with host DNA preparations. Most of the progeny from subsequent subcultures were phage sensitive, though phage production was also still measurable in the bulk culture. This combination of phage production and sensitivity suggests the sub-cultures were reverting to non-lysogenic cells. We choose to dismiss the possibility that this phage displays pseudolysogeny $[15,25,26]$ based upon the isolation history of this virus and its inducibility by Mitomycin C; and, favour unstable lysogeny under laboratory culture conditions. Similar observations have been made previously with some Vibrio and Clostridium phages [27-29].

\section{Phage $\eta$ DNA does not contain hypermodified guanine residues}

Previous research had suggested the presence of a modified base in the DNA of phage $\eta$ [22]. This was investigated by digestion of the DNA to nucleosides using a combination of DNase I, phosphodiesterase I and alkaline phosphatase coupled with HPLC separation of the products. We expected to observe a shift in the elution time of one of the four nucleoside peaks or the appearance of a fifth peak in the elution profile [30]. Neither of these were observed (Additional file 1: Figure S1), therefore there was no evidence to support the presence of a modified base. Phage molecular biologists no longer routinely calculate the mol\% GC based upon buoyant density or melting temperature [30] and restriction analyses are also becoming a thing of the past. As a consequence there is a strong possibility that DNA modifications may not be discovered since pyrosequencing reads through most modifications (Kropinski, unpublished observations). Third generation sequencing techniques may address this potential problem.

\section{Phage $\eta$ DNA is circularly permuted and terminally redundant}

Determination of the physical location and nature of the genome ends can offer insight into the mechanisms of DNA replication and packaging that a bacteriophage employs [31]. Restriction digestion profiles of phage $\eta$ DNA matched in silico predictions of a circular DNA molecule, and there was no difference in the profiles generated with ligated and unligated DNA samples (Additional file 2: Figure S2). Furthermore, there was no evidence of sub-molar fragments. Lastly, pulsed-field gel electrophoresis revealed one DNA band with no smearing or concatemeric molecules. These all suggest the 
impossible - the genome of phage $\eta$ is circular, necessitating further study.

Exonuclease digestions were carried out to processively truncate the DNA. When carried out before standard restriction digestion, the DNA bands containing the ends of the genome would be expected to become progressively smaller with increased exonuclease digestion time [31,32]. Time-controlled Bal31 exonuclease treatment followed by complete restriction digestion did not result in the decrease in molecular weight of any of the DNA restriction fragments (Figure 2A), In contrast for the control $\lambda$ DNA, band mass of the left (band $\mathrm{X}$ ) and right (band $\mathrm{Y}$ ) termini were progressively reduced (Figure 2B). Extended Bal31 exonuclease treatment caused a decrease in $\eta$ DNA concentration over time. As the exonuclease only acts on linear DNA this suggests that the $\eta$ DNA molecule is linear, as expected, and not a covalently closed circle as evidenced by the restriction mapping. As an additional approach, 16 overlapping primer pairs were designed to span the genome and give products of approximately $4 \mathrm{~kb}$. Each of the primer pairs produced a unique length PCR product which was the same size as predicted. The sum of these data suggests that the dsDNA genome is linear with a high degree of circular permutation.

\section{Genomic organization and annotation}

The genome of phage $\eta$ is 42,724 bp in length with a mol\% GC of 49.9. This value is significantly less than that of the host, $S$. marcescens at $58 \mathrm{~mol} \% \mathrm{GC}$, which is somewhat unusual for temperate phages where the overall base composition of the host and phage are usually remarkably similar (Kropinski, unpublished results). A unique 19 bp direct repeat was identified (5'-ATTGCAACTTATTTGTTTA-3'), which was found in four locations in the genome (Additional file 3: Table S1), and is possibly involved in regulation of expression.

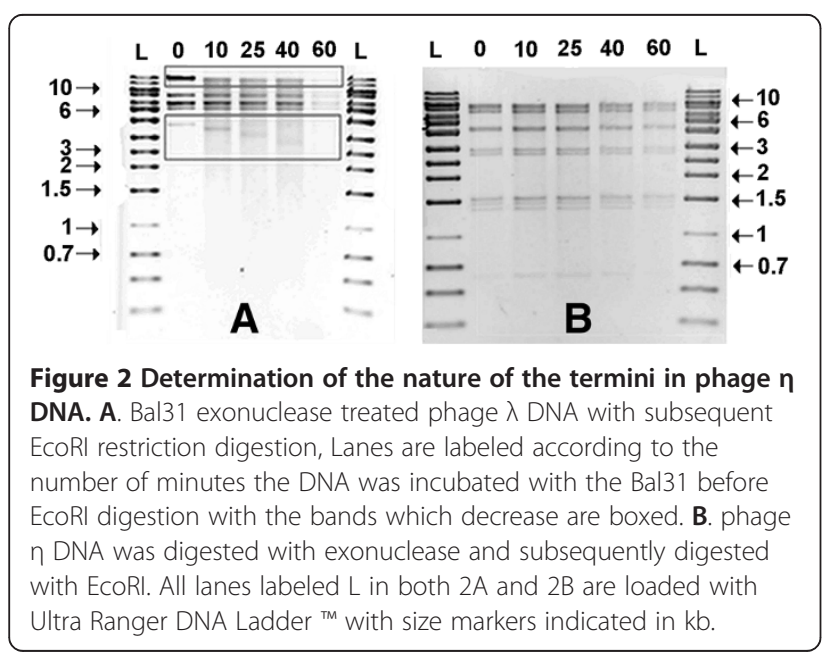

The orientation of genome annotation was chosen so that the majority of the genes were on the plus strand. Sixty-nine putative CDSs, identified during the genome annotation, are divided into four operons by four promoters and rho-independent terminators (Figure 3 ). Two potential morons (genes 45 and 60) also divide the operons, each associated with their own promoter and terminator [33]. A putative oriC was identified using Ori-Finder.

The 69 proteins were grouped into six categories based on the number of homologs and the degree of amino acid conservation. Thirteen predicted proteins (90-100\% identical sequence coverage) were very highly conserved to bacterial proteins with no homologs present in the viral database (data not shown). Nineteen predicted proteins were entirely novel. There were seven structural proteins confirmed using mass spectrometry (Additional file 4: Table S2). The fourth category contained 25 proteins which were conserved hypothetical proteins. Though based on genome organization of phage $\eta$ and related phages, a structural or morphogenesis role could be hypothesized for nine of these proteins. Of the proteins with no predicted function, four DNA-binding proteins were tentatively identified, none of them related to previously characterized phage regulatory proteins. Functional predictions could be made for the remaining 13 gene products. These functions were associated mainly with the lytic replication cycle, with protein functions involved in DNA replication, DNA packaging, structural proteins and host cell lysis. No integrase was identified during the annotation, although recombination related proteins and putative DNA-binding proteins could be identified (Additional file 3: Table S1). Some notable genes will be discussed in greater detail.

\section{Phage integration}

There are two lysogenic pathways open to temperate phages - integration into the host genome or maintenance as a plasmid. The former, as exhibited by coliphage lambda, involves recombination between homologous integration (att) sites on the phage and host genome mediated by integrase. Integration can also involve, as it does with the transposable phage such as $\mathrm{Mu}$, a transposase, leading to nonhomologous recombination, and random insertion into the host genome. Phage Eta lacks both integrase and transposase homologs. The genome of this virus shares a 33 bp sequence (GTGGAGGTGCGTGATGC CAGCAAA TGAACTGAA) located between residues 15009 and 15041 within the complete genome sequences of Serratia sp. AS13 (CP002775), Serratia sp. AS12 (CP002774) and Serratia plymuthica AS9 (CP002773). In each case, the homologous sequence is located within a prophage related to enterobacterial phage cdtI identified using PHAST [33]. In the case of strain AS13, this site was within the coding sequence of hypothetical protein 


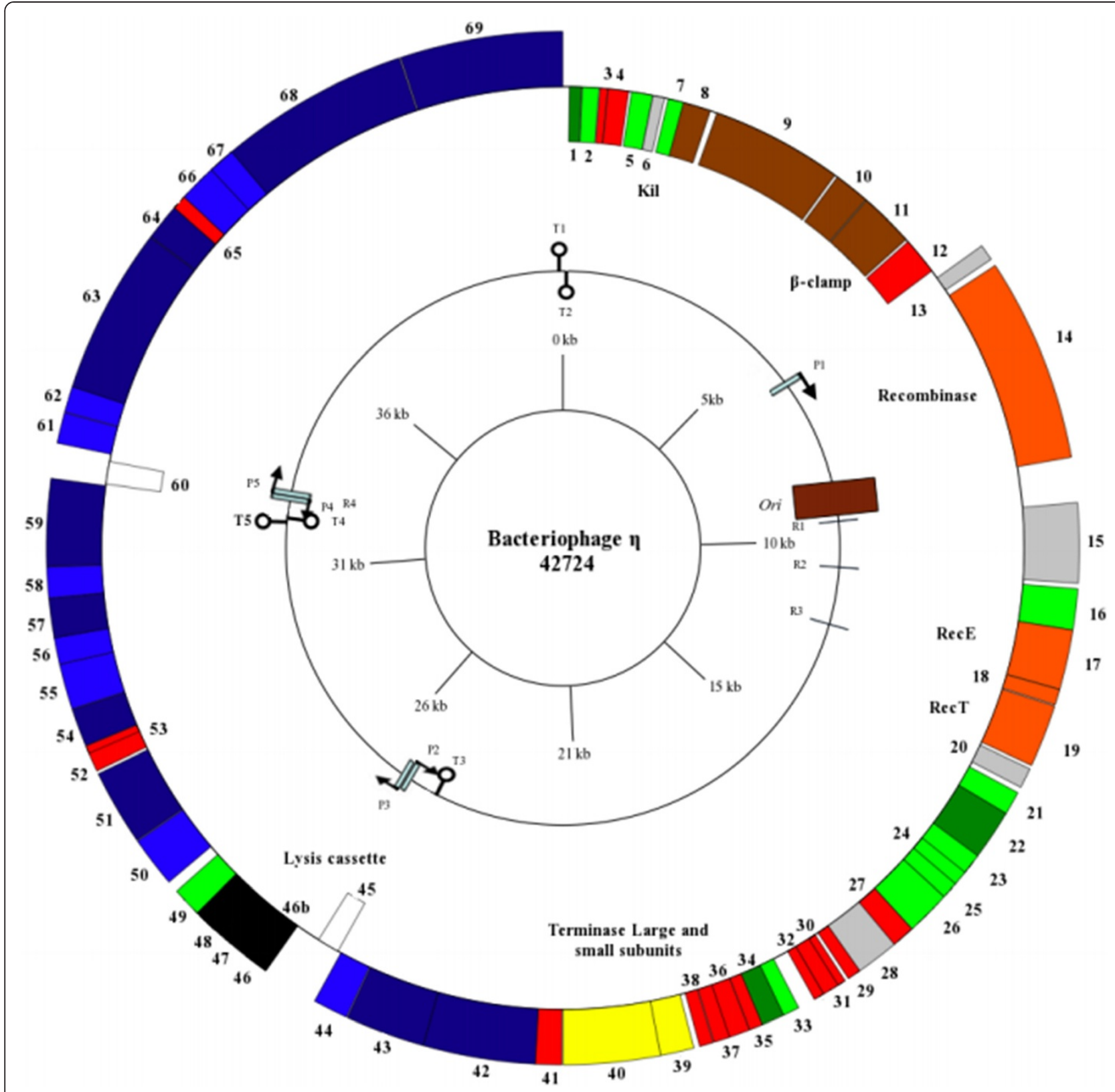

Figure $\mathbf{3}$ Genetic map of $\boldsymbol{\eta}$. The genes are color coded according to function with red: novel, light green: prophage or bacterial related, dark green: phage related, black: lysis cassette, orange: recombination, brown: replication, yellow: packaging related, dark blue; confirmed structural, light blue: hypothetical, white: morons, grey: possible DNA binding and Kil. Promoters (P), terminators (T), direct repeats (R) and the ori are also included. Promoters are indicated with black arrows on stalks, while rho-independent terminators are indicated 9 . The GenomeVx software package was used to construct this figure.

SerAS13_3448. Whether this serves as an integration site is not known; however, it is long enough that it could function in homologous recombination.

The alternative strategy is displayed by coliphage N15 [34], Yersinia phage PY54 [35], Klebsiella phage ФKO2 [36], and Halomonas aquamarina phage ФHAP-1 [37]. These phages encode protelomerase, along with partitioning proteins ParA and ParB.
Coliphage P1 also possesses ParAB homologs. A ParB homolog was identified in Eta (gene 11; Additional file 3: Table S1), though we can find no evidence for a ParS sequence nor a ParA homolog. It is possible that the prophage is maintained as a plasmid-type element, and is segregated using a combination of the phage ParB homolog (centromere-binding protein) and host factors. 


\section{DNA packaging}

Packaging of phage DNA into the precapsid during phage replication is carried out by the phage-encoded terminase holoenzyme, which is typically a heterodimer composed of large and small subunit. The large subunit of the terminase (gene 40) of phage $\eta$ was well conserved with previously identified subunits (Additional file 3: Table S1), unlike the small subunit (gene 39), which had an entirely novel $\mathrm{N}$-terminus. Basic features and domain organization in terminase enzyme complexes are shared in the tailed phages [38]. The large terminase subunit responsible for the ATPase and nuclease packaging-associated enzymatic functions, with the small terminase is involved in sequence specific substrate recognition and holoenzyme formation [39].

\section{Structural proteins}

Seven distinct bands in the SDS-PAGE gel of phage $\eta$ were identified using high resolution UPLC LTQ-FT mass spectrometry (Additional file 4: Table S2). Reliable identification was obtained by mass measurements of the peptides and high protein sequence coverage of the proteolytic fragments observed by tandem mass spectrometric (MS/MS) analyses. In the case of tailspike protein, the $\mathrm{N}$-terminus of the protein was modified by acetylation (Additional file 4: Table S2). In addition to these high abundance proteins, an additional nine proteins could be annotated as likely as structural or morphogenesis proteins (Additional file 3: Table S1). It is possible that these proteins are either present at low abundance which could not be detected on the SDSPAGE gel. While otherwise a standard lysis cassette, that of phage $\eta$ is unique in that it is located in the middle of the capsid proteins with confirmed structural proteins both upstream and downstream (Figure 3). Typically, the structural proteins are co-regulated in one operon, with the lysis cassette upstream, which allows for a simplified regulation.

\section{Genomic relatives and classification}

The structural cassette of phage $\eta$ is the only segment of the genome which showed any degree of conserved relationship with phage genome sequences available in the NCBI database. Discontiguous megablast analysis revealed that phage $\eta$ shared limited similarity $(<22 \%$ sequence coverage) with Escherichia phages $\mathrm{K} 1 \mathrm{H}$ [40] and K1G [40], Salmonella phages SETP3 [41], vB_SenS-Ent1 [42], SE2 [43], wksl3 [44], and SS3e [45]. The homologous regions were restricted to $22-43 \mathrm{~kb}$ on the $\eta$ genome, with the average shared sequence identity above $80 \%$ (Additional file 3: Table S1).

\section{Conclusions}

Serratia phage $\eta$ was originally characterized as a temperate siphovirus possessing hypermodified guanine residues in its DNA. The putative presence of hypermodified bases in a temperate phage creates a conceptual problem since expression of modifying enzymes would probably modify the host genome with catastrophic results. Our chromatographic results do not support the existence of modified bases in the DNA of this virus. Furthermore, the genomic results suggest that this phage is not classically temperate, since it lacks a demonstrable repressor and integrase homologs, but is capable of establishing an unstable relationship with its host which can best be described as unstable lysogeny. The DNA genome of phage $\eta$ is terminally redundant and highly circularly permuted. The latter observation has led other researchers [19,46-49] to the mistaken assumption that their phage genomes are circular, which has never been observed among the Caudovirales, and indeed would pose problems in DNA packaging.

Comparative genomic analysis reveals that Serratia phage $\eta$ is a unique virus which, except for the structural gene module, is unrelated to any of the current population of phages which have the complete genomes sequenced. Interestingly, the genome of its structural homolog, Salmonella phage Jersey, has recently been sequenced as part of a project to characterize the "Jerseylikevirus" genus (H. Anany, personal communication), and the only relationship between these viruses is within the morphogenesis cassette.

\section{Materials and methods}

\section{Bacteria and bacteriophages}

S. marcescens CV/rc3 (HER 1311) and phage $\eta$ were obtained from the Centre de Référence pour les Virus Bactériens Félix d'Hérelle (Université Laval, QC, Canada). The host was grown in Difco Luria-Bertani broth (LB; Fisher Scientific, Toronto, ON, Canada) at $30^{\circ} \mathrm{C}$ with shaking at $180 \mathrm{rpm}$ or on LB agar plates (LB with 1.5\% [wt/vol] agar) at $30^{\circ} \mathrm{C}$. The bacteriophage titer was determined using the double agar overlay method [48]. Phage particles were partially purified by PEG precipitation and continuous $\mathrm{CsCl}$ purification [49]. Purified phage was dialyzed using a Pierce $10 \mathrm{~K}$ Slide-A-Lyzer cassette (Thermo Fisher Scientific, Rockford, IL, USA) against 10 mM Tris-0.1 mM EDTA (pH 8.0) (TE) buffer to remove $\mathrm{CsCl}$. Purified phage was stored at $4^{\circ} \mathrm{C}$.

\section{Electron microscopy}

Purified phages were sedimented by centrifugation at 25,000 g for $60 \mathrm{~min}$, using a Beckman Coulter J-E (Palo Alto, CA) centrifuge and a JA19.1 fixed angle rotor. The pellet was washed twice under the same conditions in neutral ammonium acetate $(0.1 \mathrm{M})$. Phages were 
deposited on copper grids with carbon-coated Formvar films, stained with $2 \%$ uranyl acetate $(\mathrm{pH} 4.5)$ and examined using a Philips EM 300 electron microscope.

\section{DNA isolation, digestion and HPLC analysis: Phage}

DNA was extracted by standard phenol chloroform extraction and ethanol precipitation [50]. The purified phage $\eta$ genomic DNA was digested to the nucleoside level in preparation for HPLC analysis according to the protocol described by [30] using DNase I, phosphodiesterase I and alkaline phosphatase (Worthington Biochemical Corp. Vassar, NJ, USA). The number of units of phosphodiesterase I were increased from 0.01 units in the protocol to 0.1 units. The phosphodiesterase I and alkaline phosphatase digestions were done in a water bath at $25^{\circ} \mathrm{C}$. The digested DNA was filtered using an Ultrafree-MC membrane with a pore size of $0.1 \mu \mathrm{m}$ (Millipore Corp, Billerica, MA, USA) to remove particles in preparation for loading onto the HLPC column. Standard nucleosides were purchased from Sigma-Aldrich (SigmaAldrich, Oakville, Canada).

The protocol developed was based on the method outlined by [30]. The analysis was performed on an Agilent 1100 series LC/MSD_SL Trap system. Samples $(100 \mu \mathrm{l})$ were injected into the LC/MSD system through an Agilent 1100 series thermostated auto-sampler. Separations were carried out on a $5 \mu \mathrm{m}$ Agilent ZORBAX SB C-18 column $(4.6 \times 150 \mathrm{~mm})$ at a flow rate of $0.75 \mathrm{ml} / \mathrm{min}$. Two mobile phase solvents were used; Solvent A was $0.1 \%$ formic acid in deionized water; Solvent B was $100 \%$ HPLC grade acetonitrile. Dimethyl sulfoxide (DMSO) was used to dissolve the concentrated nucleosides. HPLC method: 98/2 A/B for five minutes then increasing to $95 / 5 \mathrm{~A} / \mathrm{B}$ at ten minutes, $80 / 20 \mathrm{~A} / \mathrm{B}$ at 12 minutes then returning to $100 \% \mathrm{~A}$.

\section{DNA sequencing and annotation}

Phage DNA was digested, ligated and treated with Bal31 exonuclease according to manufacturer's specifications (NEB) and resolved using a 1\% agarose gel. Genome end determination was carried out following protocols published by Loessner et al., [32] and Casjens et al., [51]. Pulsed-field gel analysis was carried out following the protocol of Lingohr et al., [52].

The genome sequence was determined using 454 sequencing technology at the McGill University and Genome Quebec Innovation Centre (Montreal, QC, Canada) with 49.1 fold coverage. The genome was annotated using Kodon (Applied Maths, Austin, TX, USA) with the proteins screened for homologs using the BLASTP feature of Geneious Pro 6.2 (Biomatters Ld., Auckland, New Zealand). Their molecular mass and $\mathrm{pI}$ were calculated using the Batch MW and pI Finder server at http://greengene.uml.edu/ programs/FindMW.html. Potential protein motifs were identified using the NCBI Batch CD-Search tool at http:// www.ncbi.nlm.nih.gov/Structure/bwrpsb/bwrpsb.cgi? with an E-value threshold of 0.0001. Transmembrane domains were screened for using TMHMM [53] and Phobius [54]. In certain cases HHpred $[55,56]$ was employed to analyze the protein sequences. The annotated sequence was deposited with GenBank under accession number KC460990 (GI:511624446). RNA secondary structure prediction was used to support the identification of rho-independent terminators [57]. The oriC was identified using Ori-Finder [58]. The gene diagram was constructed using Genome Vx [59].

\section{Structural protein analysis}

Phage particles which had been purified through $\mathrm{CsCl}$ twice were used for SDS-PAGE structural protein analysis. Purified whole phages were denatured at $100^{\circ} \mathrm{C}$ for $5 \mathrm{~min}$. in Laemmli Sample Buffer supplemented with 100 mM 2mercaptoethanol. The structural proteins were resolved in a Bio-Rad Ready 5-15\% Tris- $\mathrm{HCl}$ gel, in Running Buffer (25 mM Tris, $192 \mathrm{mM}$ glycine, 0.1\% SDS, pH 8.3 (Bio$\mathrm{Rad})$ ) at $150 \mathrm{~V}$ for an hour. Visible bands were excised, and then digested in-gel by sequencing-grade trypsin. The cleaved peptide fragments of the proteins were extracted using acentonitrile/0.1\% trifluoroacetic acid (TFA) (v/v, 60:40), then dried by a Savant vacuum centrifuge (Thermo Fisher Scientific, Nepean, Ontario). In the subsequent mass spectrometric analyses, the peptides were reconstituted in $8 \mu \mathrm{l}$ of $0.2 \%$ formic acid (FA) and identified using a nanoAcquity ultra-performance liquid chromatograph (UPLC, Waters, Milford, MA) - linear ion-trap Fourier transform ion cyclotron resonance (LTQ-FT ICR, Thermo Fisher, San Jose, CA) mass spectrometer. The sample was normally trapped by a reverse-phase (RP) Symmetry C18 column $(180 \mu \mathrm{m}$ i.d. $\times 20 \mathrm{~mm}$ length, $5 \mu \mathrm{m})$ at $5 \mu \mathrm{l} / \mathrm{min}$ of solvent A (0.1\% FA) for 3 minutes, and then separated through a C18 analytical column $(100 \mu \mathrm{m}$ i.d. $\times 100 \mathrm{~mm}$, $1.7 \mu \mathrm{m}, \mathrm{BEH} 130$ ) at $400 \mathrm{nl} / \mathrm{min}$ for 65 minutes. UPLC gradient was set up to a linear gradient from $5 \%$ to $30 \%$ solvent B (0.1\% FA in acetonitrile), followed by to $85 \%$ solvent B over $10 \mathrm{~min}$. for peptide elution. FT-MS scans were acquired with high resolution $(100,000)$ MS from m/z 300 to 2000 , and MS/MS measurements in linear ion-trap mode by data-dependent scans of the top eight intense precursor ions at multiply charged states of $2+, 3+$ and $4+$. Dynamic exclusion was set to a period of time at $180 \mathrm{~s}$.

Protein identification was performed using Mascot Server (version 2.3.0, Matrix Science, London, UK), and UPLC MS/MS raw data were searched against the inhouse database of the protein sequence derived from the annotated genome of phage $\eta$. The search parameters were restricted to tryptic peptides for a maximum of 2 missed cleavages. Cysteine carbamidomethylation was designated as a fixed modification, and deamidation of 
asparagine and glutamine, methionine oxidation were considered as variable modifications. Mass tolerances were set up to $10 \mathrm{ppm}$ for the FT-MS ions and $1 \mathrm{Da}$ for ion trap MS/MS fragment ions. Peptide assignments were filtered by an ion score cut off at 20 , and the identified MS/MS spectra were also verified manually.

\section{Additional files}

\begin{abstract}
Additional file 1: Figure S1. HPLC analysis Digested samples were separated using concentration gradients of $\mathrm{H}_{2} \mathrm{O}$ with $0.1 \%$ formic acid (Buffer A) and acetonitrile (Buffer B) which varied with time and are listed in Additional file 3 and in Figure 3. A mixture of the four unmodified nucleosides was used as a standard and the chromatogram produced by their separation was overlaid on the separation achieved with the experimental sample DNA. Peak elution times remained consistent and no new peaks were evident, supporting the conclusion that there is no modification present in the DNA. The small peak visible at 14 minutes was also fluorescent (fluorescence data not shown), and it was concluded to be a result of contamination of the column and unrelated to this experiment, as the concentration of acetonitrile was extremely high which would result in the elution of any contaminants. Absorbance was measured at $254 \mathrm{~nm}$.

Additional file 2: Figure S2. Restriction digestion of phage $\eta$ DNA. Lane L contains Norgen UltraRanger DNA Ladder ${ }^{\mathrm{TM}}$, with size markers indicated in $\mathrm{kb}$. The even numbered lanes contained un-ligated $n$ DNA while ligated DNA was used as the substrate in the odd numbered lanes. Lanes 1 and 2 - digested with Ndel, 3 and 4 with Bgll, and lanes 5 and 6 with EcoRI.
\end{abstract}

Additional file 3: Table S1. List of CDSs, putative promoters and terminators found in phage $\eta$. An E-value threshold of 0.0001 was used for all homology analysis.

Additional file 4: Table S2. An SDS-PAGE analysis of the purified structural phage proteins on a 12\% SDS-PAGE separation gel alongside a PageRuler ${ }^{T M}$ prestained protein ladder (Fermentas) is presented. Visible protein bands were excised from the gel, and labeled as shown in the figure. Subsequently the nature of the protein in the visible band was identified by UPLC-LTQFT -MS/MS analysis. For every detected protein the protein name, the predicted molecular size ( $\mathrm{Da})$, the maximum number of unique spectra and sequence coverage (\%) is listed.

\section{Abbreviations}

BLAST: Basic local alignment search tool; gp: Gene product; HPLC: High pressure liquid chromatography; N/A: Not applicable; CDS: Coding sequence; PFU: Plaque forming unit, a measure of the number of viable viral particles; SDS-PAGE: Denaturing polyacrylamide gel electrophoresis;

TMHMM: Transmembrane prediction using hidden Markov models.

\section{Competing interests}

The authors have no competing interests to disclose.

\section{Authors' contributions}

AMK and PJK designed and guided the project; JMD did most of the writing of the paper and the laboratory work and informatic analysis; RAM directed the HPLC nucleoside analysis; HWA did the electron microscopic examination of the phage; YMS preformed the mass spectrometry, all authors read and approved the final manuscript.

\section{Acknowledgements}

AMK was supported by a Discovery Grant from the Natural Sciences and Engineering Research Council of Canada. This funding body did not have any role in the design of the experiments, in the collection, analysis, and interpretation of data; in the writing of the manuscript; or in the decision to submit the manuscript for publication.

\section{Author details}

${ }^{1}$ Department of Molecular \& Cellular Biology, University of Guelph, Guelph, ON N1G 2W1, Canada. '2Department of Chemistry, University of Guelph, Guelph, ON N1G 2W1, Canada. ${ }^{3}$ Department of Microbiology, Immunology, and Infectiology, Faculty of Medicine, Laval University, Quebec, QC G1X 4C6, Canada. ${ }^{4}$ Shanghai Center for Plant Stress Biology, Chinese Academy of Sciences, 3888 Chenhua Road, Shanghai 201602, China. ${ }^{5}$ Laboratory for Foodborne Zoonoses, Public Health Agency of Canada, 110 Stone Road West, Guelph, Ontario N1G 3W4, Canada. ${ }^{6}$ Current address: ETH Zurich, Institute of Food, Nutrition and Health, Schmelzbergstrasse 7, 8092 Zurich, Switzerland.

Received: 18 September 2013 Accepted: 10 January 2014 Published: 16 January 2014

\section{References}

1. Wolcott RD, Gontcharova V, Sun Y, Zischakau A, Dowd SE: Bacterial diversity in surgical site infections: not just aerobic cocci any more. J Wound Care 2009, 18:317-323.

2. Bosi C, Davin-Regli A, Charrel R, Rocca B, Monnet D, Bollet C: Serratia marcescens nosocomial outbreak due to contamination of hexetidine solution. J Hosp Infect 1996, 33:217-224.

3. Perez C, Fujii Y, Fauls M, Hummel J, Breitschwerdt E: Fatal aortic endocarditis associated with community-acquired Serratia marcescens infection in a dog. J Am Anim Hosp Assoc 2011, 47:133-137.

4. Pinna A, Usai D, Sechi LA, Carta A, Zanetti S: Detection of virulence factors in Serratia strains isolated from contact lens-associated corneal ulcers. Acta Ophthalmol 2009, 89:382-387.

5. Dowzicky MJ, Park CH: Update on antimicrobial susceptibility rates among gram-negative and gram-positive organisms in the United States: results from the Tigecycline Evaluation and Surveillance Trial (TEST) 2005 to 2007. Clin Ther 2008, 30:2040-2050.

6. Samonis G, Vouloumanou EK, Christofaki M, Dimopoulou D, Maraki S, Triantafyllou E, Kofteridis DP, Falagas ME: Serratia infections in a general hospital: characteristics and outcomes. Eur J Clin Microbiol Infect Dis 2011, 30:653-660.

7. Crivaro V, Bagattini M, Salza MF, Raimondi F, Rossano F, Triassi M, Zarrilli R: Risk factors for extended-spectrum beta-lactamase-producing Serratia marcescens and Klebsiella pneumoniae acquisition in a neonatal intensive care unit. J Hosp Infect 2007, 67:135-141.

8. Rizvi M, Fatima N, Shukla I, Malik A: Epidemiology of extended spectrum beta-lactamases in Serratia and Citrobacter species in North India. Indian J Pathol Microbiol 2010, 53:193-194.

9. Hamilton RL, Brown WJ: Bacteriophage typing of clinically isolated Serratia marcescens. Appl Microbiol 1972, 24:899-906.

10. Wassermann MM, Seligmann E: Serratia marcescens bacteriophages. J Bacteriol 1953, 66:119-120.

11. Petty NK, Foulds IJ, Pradel E, Ewbank JJ, Salmond GP: A generalized transducing phage (philF3) for the genomically sequenced Serratia marcescens strain Db11: a tool for functional genomics of an opportunistic human pathogen. Microbiology 2006, 152:1701-1708.

12. Regue M, Fabregat C, Vinas M: A generalized transducing bacteriophage for Serratia marcescens. Res Microbiol 1991, 142:23-27.

13. Calendar R: Introduction. In Bacteriophages. Edited by Calendar R. Interscience publishers Inc: New York; 2006:1-6.

14. Casjens S, Winn-Stapley DA, Gilcrease EB, Morona R, Kuhlewein C, Chua JE, Manning PA, Inwood W, Clark AJ: The chromosome of Shigella flexneri bacteriophage Sf6: complete nucleotide sequence, genetic mosaicism, and DNA packaging. J Mol Biol 2004, 339:379-394.

15. Abedon ST: Disambiguating bacteriophage pseudolysogeny: an historical analysis of lysogeny, pseudolysogeny, and the phage carrier state. In Contemporary trends in bacteriophage research. Edited by Adams HT. New York: Nova Science Publishers, Inc.; 2009:285-307.

16. Friman VP, Hiltunen $T$, Jalasvuori M, Lindstedt C, Laanto E, Ormala AM, Laakso J, Mappes J, Bamford JK: High temperature and bacteriophages can indirectly select for bacterial pathogenicity in environmental reservoirs. PloS One 2011, 6:e17651.

17. Matsushita K, Uchiyama J, Kato S, Ujihara T, Hoshiba H, Sugihara S, Muraoka A, Wakiguchi H, Matsuzaki S: Morphological and genetic analysis of three bacteriophages of Serratia marcescens isolated from environmental water. FEMS Microbiol Lett 2009, 291:201-208.

18. Yu L, Wen Z, Yang W, Li N, Wang J, Lu J, Li J: Isolation and characterization of Serratia marcescens phage. Wei sheng wu xue bao 2008, 48:498-502.

19. Matilla MA, Salmond GP: Complete Genome Sequence of Serratia plymuthica Bacteriophage MMAM1. J Virol 2012, 86:13872-13873. 
20. Adriaenssens EM, Ackermann HW, Anany H, Blasdel B, Connerton IF, Goulding D, Griffiths MW, Hooton SP, Kutter EM, Kropinski AM, Lee JH, Maes M, Pickard D, Ryu S, Sepehrizadeh Z, Shahrbabak SS, Toribio AL, Lavigne R: A suggested new bacteriophage genus: "Viunalikevirus". Arch Virol 2012, 157:2035-2046.

21. Lavigne R, Darius P, Summer EJ, Seto D, Mahadevan P, Nilsson AS, Ackermann HW, Kropinski AM: Classification of Myoviridae bacteriophages using protein sequence similarity. BMC Microbiol 2009, 9:224.

22. Pons FW: Untersuchung der DNS einiger Serratiastämme und deren Phagen. Biochemische Zeit 1966, 346:26-40.

23. Ackermann HW, Gershman M: Morphology of phages of a general Salmonella typing set. Res Virol 1992, 143:303-310.

24. Bradley DE: The morphology and physiology of bacteriophages as revealed by the electron microscope. J R Microsc Soc 1965, 84:257.

25. Łoś M, Węgrzyn G: Pseudolysogeny. Adv Virus Res 2012, 82:339-349.

26. Miller RV, Day MJ: Contribution of lysogeny, pseudolysogeny and starvation to phage ecology. In Bacteriophage ecology: population growth, evolution, and impact of bacterial viruses. advances in molecular and cellular microbiology series. Edited by Abedon ST. Cambridge, UK: Cambridge University Press; 2008:114-146.

27. Khemayan K, Pasharawipas T, Puiprom O, Sriurairatana S, Suthienkul O, Flegel TW: Unstable lysogeny and pseudolysogeny in Vibrio harveyi siphovirus-like phage 1. Appl Environ Microbiol 2006, 72:1355-1363.

28. Sakaguchi Y, Hayashi T, Kurokawa K, Nakayama K, Oshima K, Fujinaga Y, Ohnishi M, Ohtsubo E, Hattori M, Oguma K: The genome sequence of Clostridium botulinum type $\mathrm{C}$ neurotoxin-converting phage and the molecular mechanisms of unstable lysogeny. Proc Natl Acad Sci U S A 2005, 102:17472-17477.

29. Pasharawipas T, Thaikua S, Sriurairatana S, Ruangpan L, Direkbusarakum S, Manopvisetcharean J, Flegel TW: Partial characterization of a novel bacteriophage of Vibrio harveyi isolated from shrimp culture ponds in Thailand. Virus Res 2005, 114:63-69.

30. Manderville RAM, Kropinski AM: Approaches to the compositional analysis of DNA. In Bacteriophages: methods and protocols, volume 2: molecular and applied aspects. Edited by Clokie MRJ, Kropinski AM. Totowa, NJ: Humana Press; 2009:11-18.

31. Casjens SR, Gilcrease EB: Determining DNA packaging strategy by analysis of the termini of the chromosomes in tailed-bacteriophage virions. In Bacteriophages: methods and protocols, volume 2: molecular and applied aspects. Edited by Clokie MRJ, Kropinski AM. Totowa, NJ: Humana Press; 2009:91-111.

32. Loessner MJ, Inman RB, Lauer P, Calendar R: Complete nucleotide sequence, molecular analysis and genome structure of bacteriophage A118 of Listeria monocytogenes: implications for phage evolution. Mol Microbiol 2000, 35:324-340.

33. Zhou Y, Liang Y, Lynch KH, Dennis JJ, Wishart DS: PHAST: a fast phage search tool. Nucleic Acids Res 2011, 39(Web Server issue):W347-W352.

34. Ravin NV: N15: The linear plasmid prophage. In The Bacteriophages. Edited by Calendar R. New York, NY: Oxford University Press; 2006:448-456.

35. Hammerl JA, Klein I, Appel B, Hertwig S: Interplay between the temperate phages PY54 and N15, linear plasmid prophages with covalently closed ends. J Bacteriol 2007, 189:8366-8370

36. Casjens SR, Gilcrease EB, Huang WM, Bunny KL, Pedulla ML, Ford ME, Houtz JM, Hatfull GF, Hendrix RW: The pKO2 linear plasmid prophage of Klebsiella oxytoca. J Bacteriol 2004, 186:1818-1832.

37. Mobberley JM, Authement RN, Segall AM, Paul JH: The temperate marine phage ФHAP-1 of Halomonas aquamarina possesses a linear plasmid-like prophage genome. J Virol 2008, 82:6618-6630.

38. Zhang X, Studier FW: Multiple roles of T7 RNA polymerase and T7 lysozyme during bacteriophage T7 infection. J Mol Biol 2004, 340:707-730.

39. Kanamaru S, Kondabagil K, Rossmann MG, Rao VB: The functional domains of bacteriophage T4 terminase. J Biol Chem 2004, 279:40795-40801.

40. Bull JJ, Vimr ER, Molineux IJ: A tale of tails: Sialidase is key to success in a model of phage therapy against K1-capsulated Escherichia coli. Virology 2010, 398:79-86.

41. De Lappe N, Doran G, O'Connor J, O'Hare C, Cormican M: Characterization of bacteriophages used in the Salmonella enterica serovar Enteritidis phage-typing Scheme. J Med Microbiol 2009, 58:86-93.

42. Turner D, Hezwani M, Nelson S, Salisbury V, Reynolds D: Characterization of the Salmonella bacteriophage vB_SenS-Ent1. J Gen Virol 2012, 93:2046-2056.

43. Tiwari BR, Kim S, Kim J: Complete genomic sequence of Salmonella enterica serovar Enteritidis phage SE2. J Virol 2012, 86:7712.
44. Kang HW, Kim JW, Jung TS, Woo GJ: wksl3, a New biocontrol agent for Salmonella enterica serovars enteritidis and typhimurium in foods: characterization, application, sequence analysis, and oral acute toxicity study. Appl Environ Microbiol 2013, 79:1956-1968.

45. Kim SH, Park JH, Lee BK, Kwon HJ, Shin JH, Kim J, Kim S: Complete genome sequence of Salmonella bacteriophage SS3e. J Virol 2012, 86:10253-10254

46. Salifu SP, Valero-Rello A, Campbell SA, Inglis NF, Scortti M, Foley S, VázquezBoland JA: Genome and proteome analysis of phage E3 infecting the soil-borne actinomycete Rhodococcus equi. Environ Microbiol Rep 2013, 5:170-178.

47. Fan $\mathrm{H}$, Fan $\mathrm{H}, \mathrm{An} \mathrm{X}$, Huang $\mathrm{Y}$, Zhang Z, Mi Z, Tong Y: Complete genome sequence of IME11, a new N4-like bacteriophage. J Virol 2012, 86:13861.

48. Jeon J, Kim JW, Yong D, Lee K, Chong Y: Complete genome sequence of the podoviral bacteriophage YMC/09/02/B1251 ABA BP, which causes the lysis of an OXA-23-producing carbapenem-resistant Acinetobacter baumannii isolate from a septic patient. J Virol 2012, 86:12437-12438.

49. Lee YD, Park JH: Complete genome of temperate phage ENT39118 from Cronobacter sakazakii. J Virol 2012, 86:5400-5401.

50. Sambrook J, Russell DW: Molecular cloning - a laboratory manual, vol 1-3. 3rd edition. New York: Cold Spring Harbor Laboratory Press; 2001.

51. Adams MH: Methods of study of bacterial viruses. In Bacteriophages. New York: Interscience publishers, Inc; 1959:443-457.

52. Lingohr EJ, Frost S, Johnson RP: Determination of bacteriophage genome size by pulsed-field gel electrophoresis. In Bacteriophages: methods and protocols, volume 2: molecular and applied aspects. Edited by Clokie MRJ, Kropinski AM. Totowa, NJ: Humana Press; 2009:19-26.

53. Krogh A, Larsson B, von Heijne G, Sonnhammer EL: Predicting transmembrane protein topology with a hidden Markov model: application to complete genomes. J Mol Biol 2001, 305:567-580.

54. Käll L, Krogh A, Sonnhammer EL: A combined transmembrane topology and signal peptide prediction method. J Mol Biol 2004, 338:1027-1036.

55. Hildebrand A, Remmert M, Biegert A, Söding J: Fast and accurate automatic structure prediction with HHpred. Proteins 2009, 77:128-132

56. Sonnhammer EL, von Heijne G, Krogh A: A hidden Markov model for predicting transmembrane helices in protein sequences. Proc Int Conf Intell Syst Mol Biol 1998, 6:175-182.

57. Zuker M: Mfold web server for nucleic acid folding and hybridization prediction. Nucl Acids Res 2003, 31:3406-3415.

58. Goa F, Zhang CT: Ori-finder: a web-based system for finding oriCs in unannotated bacterial genomes. BMC Bioinformatics 2008, 9:79.

59. Conant GC, Wolfe KH: GenomeVX: simple web-based creation of editable circular chromosome maps. Bioinformatics 2008, 6:861.

doi:10.1186/1743-422X-11-6

Cite this article as: Denyes et al:: The genome and proteome of Serratia bacteriophage $\eta$ which forms unstable lysogens. Virology Journal 2014 11:6

\section{Submit your next manuscript to BioMed Central and take full advantage of:}

- Convenient online submission

- Thorough peer review

- No space constraints or color figure charges

- Immediate publication on acceptance

- Inclusion in PubMed, CAS, Scopus and Google Scholar

- Research which is freely available for redistribution 